\title{
Pattern and Treatment of Vitiligo at Tertiary Health Care Level in Dhaka City
}

\author{
Madhabi Lata Shuma ${ }^{1}$, Shimul Halder ${ }^{2}$ and Md. Motiur Rahman ${ }^{2}$ \\ ${ }^{1}$ Department of Pharmacy, Stamford University, 51 Siddeswari Road, Ramna, Dhaka-1217, Bangladesh \\ ${ }^{2}$ Department of Pharmaceutical Technology, University of Dhaka, Dhaka-1000, Bangladesh
}

Received: April 30, 2014; Accepted: May 18, 2014; Published (web): June 29, 2014

\begin{abstract}
The etiopathogenesis of depigmentation in vitiligo is still obscure that constitutes a major psychological health problem in Bangladesh. So our sociodemographic study represents the pattern and treatment of vitiligo at tertiary level of healthcare in Dhaka city. It has helped to identify the drugs used for the treatment of this disease. A total of 100 (70 male and 30 female) patients were interviewed at the Department of Dermatology and Venereology in Bangabandhu Sheikh Mujib Medical University Hospital (BSMMUH) to conduct the study. It was observed that, the urban (62\%) and upper-middle class people (55\%) were most commonly affected by the disease. The most common signs of vitiligo were pale skin (45\%) and itching (26\%) and the drugs used to manage vitiligo were mainly methoxsalen (83\%), riboflavin (53\%), tacrolimus (49\%), zinc sulphate B.P. (52\%), tri-methyl solaren (55\%), pimecrolimus ( $42 \%$ ) and monobenzone $(12 \%)$. Our population-based data provided evidence for a protective effect of vitiligo and supported the purported protective role against this disease.
\end{abstract}

Key words: Vitiligo, dermatology, venerology, sociodemographic

\section{INTRODUCTION}

Vitiligo is an acquired disease characterized principally by patchy depigmentation of skin and overlying hair. ${ }^{1}$ Generalized vitiligo (GV), the predominant form of the disorder, results from autoimmune loss of melanocytes from affected regions. $^{2}$ It is clinically characterized by the development of white macules. ${ }^{3}$ The most common form is non-segmental vitiligo, which tends to appear in symmetric patches, sometimes cover large areas of the body. ${ }^{4}$ The prevalence of the disease is around $1 \%$ in the United States and in Europe, but ranges from less than $0.1 \%$ to greater than $8 \%$ worldwide. $^{2}$ Women are more prone to develop this disease due to cosmetic related issues. ${ }^{2}$ Fifty percent of the patients develop the disease before the of age 20 years. It also commences at an advanced age but is unusual, and may be associated with diseases like, thyroid dysfunction, rheumatoid arthritis, diabetes mellitus, and alopecia areata. ${ }^{3}$

Correspondence to: Shimul Halder

E. mail: shimulpht@du.ac.bd

Dhaka Univ. J. Pharm. Sci. 13(1): 93-96, 2014 (June)
The course of the disease is unpredictable and the response to treatment varies. Depigmentation may be the source of severe psychological distress, diminished quality of life, and increased risk of psychiatric morbidity. ${ }^{3}$ Vitiligo most often affects the face, elbows and knees, hands and feet, and genitals. It is more noticeable in darker-skinned people because of the contrast of white patches against dark skin. No other skin changes occur.

Medical treatment for vitiligo isn't always necessary for some paients because the skin color returns to normal without treatment. ${ }^{5}$ For others, selfcare steps, such as using sunscreen and applying cosmetic camouflage cream, may improve the appearance of skin. ${ }^{5}$ Depending on the number, size and location of the white patches, patients may decide to seek medical treatment. Medical treatments for vitiligo aim to even out skin tone, either by restoring color (pigment) or by destroying the remaining color. Treatment for vitiligo may take as long as 6 to 18 months.

There are a variety of therapeutic possibilities including topical corticosteroids, topical calcineurin 
inhibitors, as well as phototherapy with Psoralen plus UVA (PUVA), narrow-band UVB, and a 308-nm excimer laser and/or lamps. ${ }^{6}$ Furthermore, surgical methods encompass grafting and transplantation while depigmentation treatments and psychological support may also be considered. These treatment options have limited success ${ }^{7-9}$ and some present significant risks, including suspected increases in skin cancer risk by PUVA, skin atrophy with corticosteroids, and skin boils with UVB therapy. ${ }^{7-9}$ Some alternative traditional medications are also used for this purpose. A systematic review of natural health product (NHP) treatments for vitiligo ${ }^{10}$ identified several approaches showing positive results, including topical tocopherol, ${ }^{11}$ topical vitamin $\mathrm{D}_{3}{ }^{12,13}$, oral 1-phenylalanine ${ }^{14,15}$ and Ginkgo biloba. ${ }^{16}$

\section{MATERIALS AND METHODS}

The present protocol consists of brief description of study type, study duration, study design, inclusion and exclusion criteria, operational modality and fieldwork.

Study type. Cross sectional.

Study duration. 3 months.

Study design. The survey was conducted for the determination of pattern and treatment of vitiligo at tertiary health care level in Dhaka city from $2^{\text {nd }}$ July, 2012 to $30^{\text {th }}$ September, 2012. A survey of 100 patients exhibiting the signs and symptoms of vitiligo was conducted.

Inclusion and exclusion criteria. All the patients of vitiligo came for treatment at the Department of Dermatology and Venereology in BSMMUH and during this period the patients were studied. The patients who did not develop enough signs and symptoms of vitiligo were excluded from the study.

Operational modality. Information on age, sex, biophysical characteristics, diagnosis, treatment, suspected drugs causing vitiligo, duration of hospital stay, type of vitiligo, and drugs used to manage the vitiligo were analyzed by using Microsoft Office Excel 2007 Software.
Field work. Five interviewers were dedicated to conduct personal interview. All the interviewers had the theoretical as well as practical knowledge of data collection techniques and the disease concerned. Patients were informed about purpose of the study; each patient who was satisfied to participate in the study signed an informed consent form. They were advised to continue their diet and physical activity habits without any changes during intervention.

The study was carried out by recording the patients age, sex and duration of diseases and randomly divided the patients into intervention and control groups. In this sociodemographic study, occupation of patients, family history, life living status, food habits and social problem were recorded.

Data collection form. The data collection form consisted of patient's identification number, his/her name, sex, marital status, age, personal history, age distribution etc. The questionnaires also included causes of vitiligo, signs and symptoms of the disease, side effects, different treatment methodologies, various home remedies and other alternative treatments.

\section{RESULTS AND DISCUSSION}

Socio demographic studies of a total of 100 (70 male and 30 female) patients with vitiligo were conducted at BSMMUH in Dhaka district. The results are depicted in Tables 1 to 7.

Table 1. Types of vitiligo

\begin{tabular}{lc}
\hline Types & Percentage (\%) \\
\hline Primary & 93 \\
Secondary (burns, injury, skin & 7 \\
diseases, chronic eczema etc.) & \\
\hline
\end{tabular}

Table 2. Causes of vitiligo

\begin{tabular}{lc}
\hline Cause & Percentage $(\%)$ \\
\hline Excessive mental worry & 2 \\
Chronic or acute gastric disorder & 25 \\
Burn injuries & 13 \\
Worms or other parasites in the alimentary & 21 \\
canal & \\
Physical trauma & 5 \\
Sunburn & 2 \\
Hereditically & 5 \\
Others & 27 \\
\hline
\end{tabular}


In this study, pattern and treatment of vitiligo at tertiary health care level in Dhaka city were analyzed. About $13 \%$ of the people think that vitiligo is caused by burn injuries and $21 \%$ of the people feel that it occurs due to worms or other parasitic invasion in the alimentary canal. Pale skin (45\%), itching (26\%), and pain $(12 \%)$ were the predominant signs and symptoms of vitiligo.

Table 3. Signs and symptoms of vitiligo

\begin{tabular}{ll}
\hline Sign and symptoms & Percentage (\%) \\
\hline Pale skin & 45 \\
Pain & 12 \\
Itching & 26 \\
Rash & 10 \\
Others & 7 \\
\hline
\end{tabular}

Table 4. Diagnosis of vitiligo

\begin{tabular}{lc}
\hline Tests & Percentage (\%) \\
\hline Medical history & 15 \\
Laboratory test & 54 \\
Microscopic test & 37 \\
Blood test & 65 \\
KOH test & 19 \\
Any other test & 27 \\
\hline
\end{tabular}

Table 5. Types of drugs used in the treatment of vitiligo

\begin{tabular}{lc}
\hline Types of Drugs & Percentage $(\%)$ \\
\hline Methoxsalen & 83 \\
Riboflavin & 53 \\
Zinc sulphate B.P & 52 \\
Tri methyl solaren & 55 \\
Pimecrolimus & 42 \\
Tacrolimus & 49 \\
Monobenzone & 12 \\
\hline
\end{tabular}

Table 6. Prevention of vitiligo

\begin{tabular}{lc}
\hline Type & Percentage (\%) \\
\hline Enhancing melanocyte formation & 72 \\
Controling genetic disposition & 42 \\
Correcting the hormonal imbalance & 38 \\
Helping body cope up with stress and & 30 \\
emotional pressures & \\
Taking safe blood & 26 \\
\hline
\end{tabular}

Table 7. Side effects (due to specific drug)

\begin{tabular}{lc}
\hline Type & Percentage (\%) \\
\hline Hereditary factors & 13.5 \\
Physical illness & 24.3 \\
Emotional stress & 16.2 \\
Worms & 45.9 \\
\hline
\end{tabular}

The most common drugs used in the treatment of vitiligo include, zinc sulphate B.P. (52\%), riboflavin (53\%), methoxasalen (83\%), tacrolimus (49\%), trimethyl solaren (55\%), and pimecrolimus (42\%). Some side effects associated with drug treatment involved physical illness, emotional stress and worms.

\section{CONCLUSION}

As vitiligo is becoming a social problem in Bangladesh, the social awareness about the vitiligo and sociodemographic studies on Vitiligo are essential in Bangladesh. Due to the lack of proper knowledge and systemic monitoring, the number of vitiligo patients is increasing day by day. Urban people are more prone to develop signs and symptoms of vitiligo as compared to the rural people. Moreover, patients with vitiligo are often disliked and thus the tendency to hide the disease from others is also prominent which results in further outbreak of the disease. A social awareness program regarding this disease along with proper diagnostic and monitoring tool should be developed immediately in order to combat this disease properly.

\section{ACKNOWLEDGEMENT}

The authors wish to thank the Department of Dermatology and Venereology in the BSMMUH for their support to collect data from patients.

\section{REFERENCES}

1. Rahman, M.H., Amin, M.Z., Rahman, M. and Satter, M.A. 2013. A demographic study on vitiligo (sheti) in Bangladesh. Int. J. Res. Med. Sci. 1, 123-28.

2. Richard, A. 2011. Recent progress in the genetics of generalized vitiligo. J. Gen. Gen. 38, 271-278.

3. Ali, A., Lesley. M., Felsten, M. and Daly, V. 2011. Vitiligo: A comprehensive overview: Part I. Introduction, epidemiology, quality of life, diagnosis, differential diagnosis, associations, histopathology, etiology, and workup. J. Am. Acad. Derm. 65, 473-491.

4. Halder, R.M. and Chappell, J.L. 2009. "Vitiligo update". Seminars in Cutaneous Med. Surg. 28, 86-92.

5. www.mayoclinic.com/health/vitiligo/DS00586/DSECTION= treatments-and-drugs 
6. Alauldin. K., Alhowaish, N., Dietrich, M. and Klaus, F. 2013. Effectiveness of a 308-nm excimer laser in treatment of vitiligo: a review. Lasers in Med. Sci. 28, 1035-1041.

7. Whitton, M.E., Ashcroft, D.M., Barrett, C.W. and Gonzalez, U. 2007. Interventions for vitiligo. Cochrane Database of Systematic Reviews.143, 643-6.

8. Grimes, P. 2005. New insights and new therapies in Vitiligo. J. Am. Med. Assoc. 293,730-735.

9. Forschner, T., Buchholtz, S. and Stockfleth, E. 2007. Current state of vitiligo therapy--evidence-based analysis of the literature. J. der Deut. Derm. Gesellschaft. 5, 467-475.

10. Szczurko, O. and Boon, H. 2008. A systematic review of natural health product treatment for vitiligo. BMC Derm. 8, 2

11. Panin, G., Strumia, R. and Ursini, F. 2004. Topical [alpha]Tocopherol Acetate in the Bulk Phase: Eight Years of Experience in Skin Treatment. Annals New York Acad. Sci. 1031, 443-447.
12. Ichiro, K., Aki, M.A., Kumiko, E. and Sang, J.B. 2002. Vitamin D3 and solar irradiation in the treatment of vitiligo vulgaris. J. Europ. Acad. Derm. Vene. 16 (Supplement 1), 341.

13. Shigetoshi, S. 2002. Treatment of vitiligo with vitamin D3 (tacalcitol). J.Europ. Acad. Derm. Vener. 16 (Supplement 1), 275.

14. Siddiqui, A.H., Stolk, L.M.L., Bhaggoe, R., Hu, R., Schutgens, R.B.H. and Westerhof, W. 1994. L-Phenylalanine and UVA irradiation in the treatment of vitiligo. Dermatology. 188, 215-218.

15. Cormane, R.H., Siddiqui, A.H., Westerhof, W. and Schutgens, R.B. 1985. Phenylalanine and UVA light for the treatment of vitiligo. Arch. Derm. Res. 277, 126-130.

16. Parsad, D., Pandhi, R. and Juneja, A. 2003. Effectiveness of oral Ginkgo biloba in treating limited, slowly spreading vitiligo. Clin. Exp. Derm. 28, 285-287. 